\title{
Erratum
}

\section{Erratum to "Ferritin in Adult-Onset Still's Disease: Just a Useful Innocent Bystander?”}

\author{
Bella Mehta ${ }^{1}$ and Petros Efthimiou ${ }^{1,2}$ \\ ${ }^{1}$ Rheumatology Division, Lincoln Medical and Mental Health Center, New York, NY 10451, USA \\ ${ }^{2}$ Department of Medicine, Weill Cornell Medical College, New York, NY 10021, USA
}

Correspondence should be addressed to Petros Efthimiou, pe53@cornell.edu

Received 5 July 2012; Accepted 24 July 2012

Copyright (C) 2012 B. Mehta and P. Efthimiou. This is an open access article distributed under the Creative Commons Attribution License, which permits unrestricted use, distribution, and reproduction in any medium, provided the original work is properly cited.

There is an error in the citations of our previous paper as reference [51] G. Zandman-Goddard, M. Blank, P. Langevitz et al., "Antiserum amyloid component $P$ antibodies in patients with systemic lupus erythematosus correlate with disease activity," Annals of the Rheumatic Diseases, vol. 64, no. 12, pp. 1698-1702, 2005 should be replaced by the following references: [1] Li, X., et al., "Epidermal Growth Factor-Ferritin H-Chain Protein Nanoparticles for Tumor Active Targeting," Small, 2012; [2] Jezequel, P., et al., "Validation of tumorassociated macrophage ferritin light chain as a prognostic biomarker in node-negative breast cancer tumors: A multicentric 2004 national PHRC study," International Journal of Cancer, 2012. 131(2): p. 426-37. [3] Pitcher, J., et al., "Disruption of neuronal CXCR4 function by opioids: preliminary evidence of ferritin heavy chain as a potential etiological agent in neuroAIDS," Journal of Neuroimmunology, 2010. 224(12): p. 66-71. [4] Rosen, H. R., "Placental isoferritin-associated p43 in pregnancy and breast cancer: minireview," Neoplasma, 1996. 43(6): p. 357-62. 


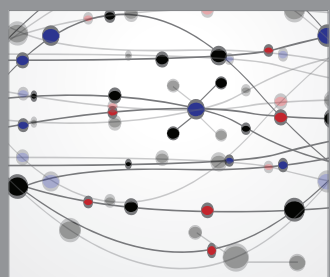

The Scientific World Journal
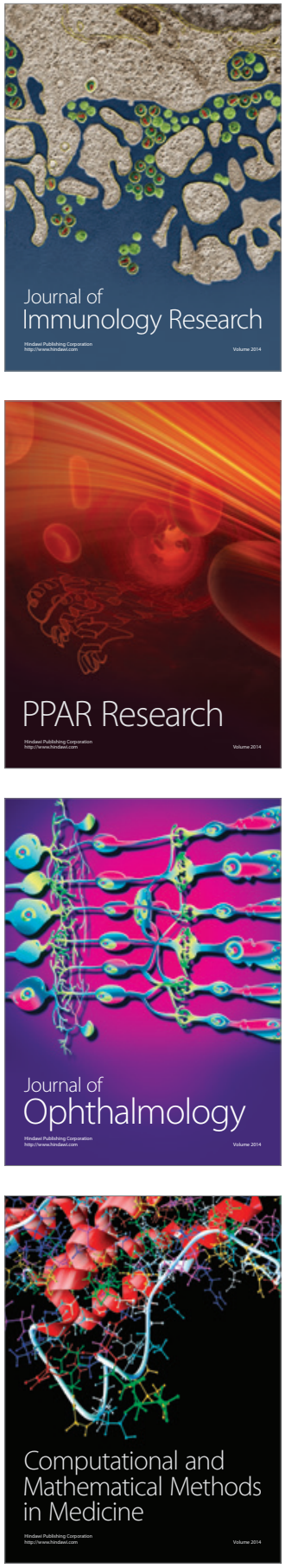

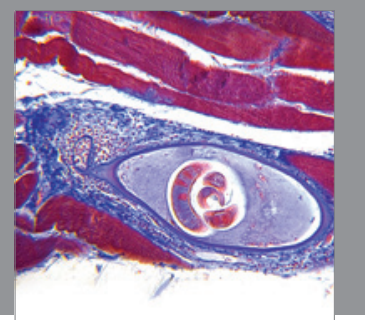

Gastroenterology

Research and Practice
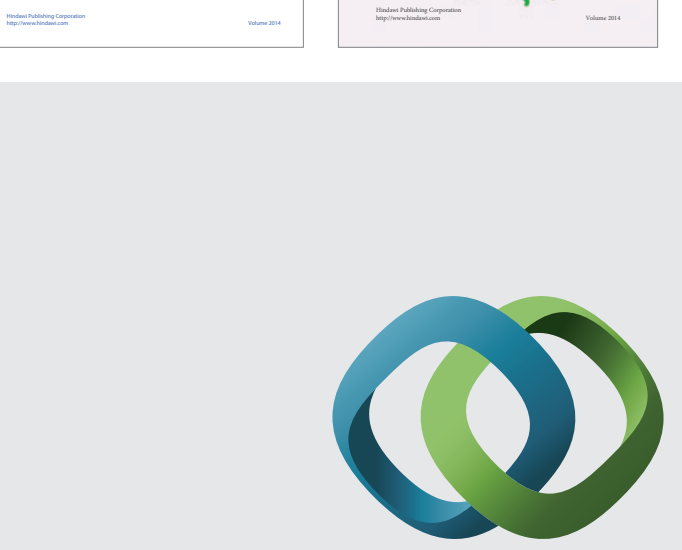

\section{Hindawi}

Submit your manuscripts at

http://www.hindawi.com
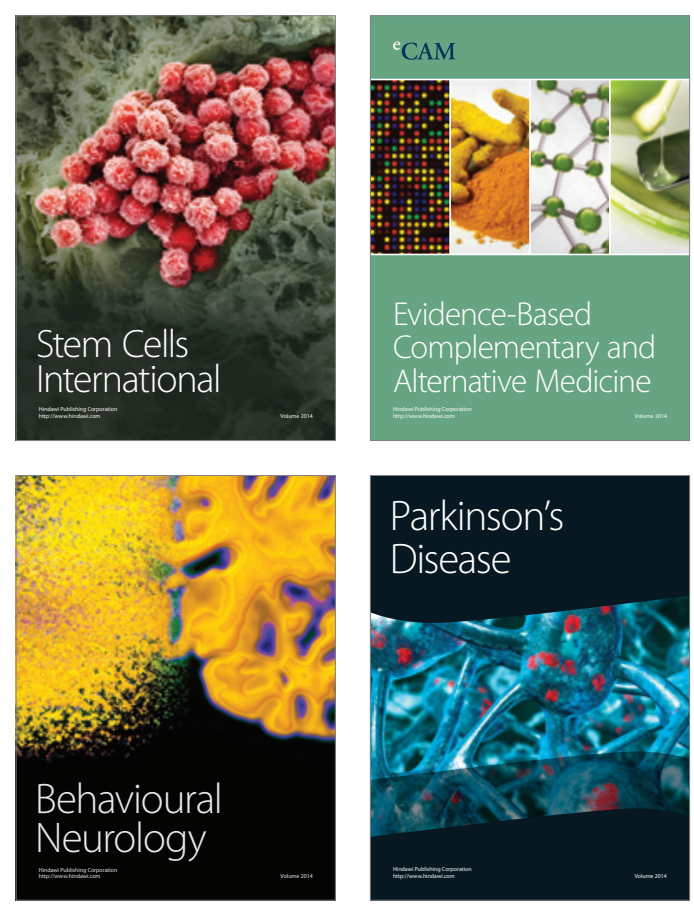

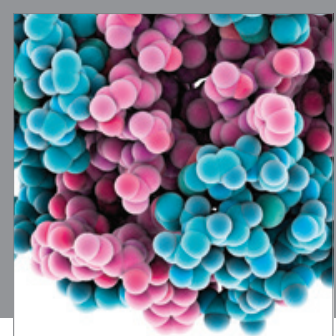

Journal of
Diabetes Research

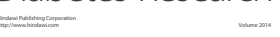

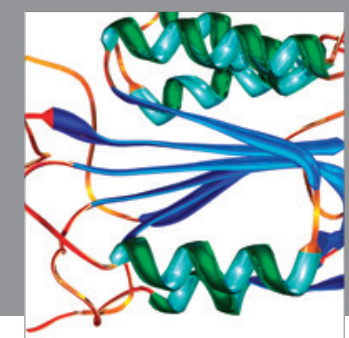

Disease Markers
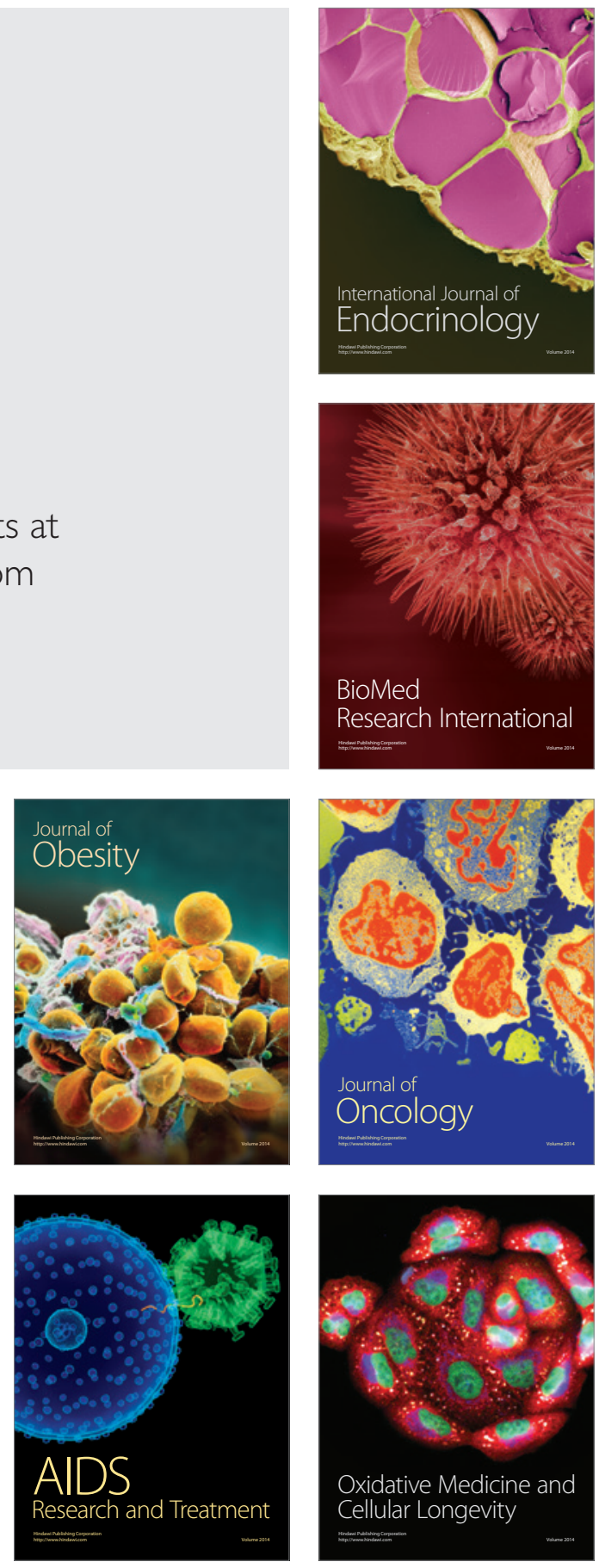